\title{
QUESTÕES SOBRE ENSINO DE LITERATURA
}

\section{SUBJECTS ON TEACHING OF LITERATURE}

\author{
Danglei Castro Pereira ${ }^{1}$ \\ Glaucia Bereta ${ }^{2}$
}

\begin{abstract}
RESUMO: A problemática dos paradigmas formativos do Canon literário ganhou destaque no cenário da critica literária brasileira nos últimos anos. A reflexão discute a influência do olhar canônico no ensino de literatura nos últimos anos. Acreditamos que a situação fragmentária do ensino de literatura reflete um distanciamento paulatino do leitor em formação face às obras literárias Stricto Sensu em ambiente escolar. A investigação provém de discussões realizadas dentro do projeto de dois projetos de pesquisa: "O ensino de literaturas em Língua portuguesa em escolas estaduais de Campo Grande/MS", projeto com apoio financeiro do Edital Universal 014/2009 do FUNDECT/MS e do projeto de pesquisa "O ensino de literaturas em Língua portuguesa em escolas estaduais de Campo Grande/MS", projeto com apoio do Edital MCTI /CNPq /MEC/CAPES N $\cong 07 / 2011$. Acreditamos que oportunizar o contato do leitor com textos literários em ambiente escolar de forma a valorizar a reflexão estética e a presença de qualidades artísticas é um dos caminhos para a construção de leitores críticos, capazes de apreender a qualidade de autores como Joaquim de Sousa Andrade, Sousândrade, corpus selecionado no artigo. Entendemos, com isso, que a constante revisão do cânone literário indica um caminho interessante na valorização do ensino de literatura para além dos limites cristalizados pela visão canônica tradicional. A ideia ao apresentarmos a obra poética de Sousândrade, é discutir a relação entre cânone, Historiografia literária e o ensino de literatura no contexto contemporâneo.
\end{abstract}

PALAVRAS-CHAVE: revisão de cânone; cultura brasileira; leitura literária.

ABSTRACT: Problematic of the formative paradigms of literary Canon it won prominence in the scenery of the it criticizes literary Brazilian in the last years. To present reflection the influence of the canonical glance discusses in the literature teaching in the contemporary. We believed that the fragmentary situation of the literature teaching is reflected the reader's estrangement the formation with literary works Stricto Sensu in school atmosphere. The investigation of discussions accomplished inside of the research projects: "O ensino de literaturas em Língua portuguesa em escolas estaduais de Campo Grande/MS"; "O ensino de literaturas em Língua portuguesa em escolas estaduais de Campo Grande/MS". We believed the reader's contact with literary texts in atmosphere form scholar to value the aesthetic reflection and the presence of qualities is one of the roads for the critical, capable readers' construction to apprehend the authors' quality as Joaquim de Sousa Andrade, Sousândrade, corpus the article. We understood, with that, that the constant revision of the literary canon indicates an interesting road in the discussion of the literature teaching for besides the limits crystallized by the traditional canonical vision. The idea is to discuss the relationship among canon, literary Historiography and the literature teaching in the contemporary context.

\footnotetext{
${ }^{1}$ Doutor em Letras pela Universidade Estadual Paulista "Julio de Mesquita Filho", Campi S.J.R.P. Professor de Literatura e cultura brasileira na Universidade Estadual de Mato Grosso do Sul (UEMS). E-mail: danglei@uems.br

${ }^{2}$ Graduada em Letras pela Universidade Estadual de Mato Grosso do Sul (UEMS).
} 
KEYWORDS: Canon Revision; Brazilian culture; Literary Reading

\section{Introdução}

Um dos instrumentos de manutenção e afirmação do Canon literário está presente nos manuais de teoria e critica literária destinados ao ensino de literatura e teoria literária nos cursos de Graduação e Pós-Graduação em Letras; bem como nos Livros Didáticos destinados ao ensino de literatura na Educação Básica. Por manuais de Teoria e crítica literária entendemos os compêndios que visam apresentar recortes temporais, listando obras e analisando sob uma ótica teórica, explicita ou não, a diversidade literária brasileira. Por Livros Didáticos (LD) entendemos a enorme variedade de livros e apostilas destinados ao ensino de Língua e literatura na Educação Básica. Tantos os compêndios e manuais quanto O LD serão denominados, no limite deste trabalho, como Materiais de Apoio Pedagógico (MAP).

No Brasil pensamos em manuais e compêndios representativos como, por exemplo, História concisa da Literatura brasileira, de Alfredo Bosi (1993), Formação da literatura brasileira, de Antônio Cândido (2000), A Literatura no Brasil, de Afrânio Coutinho (1969), entre outras. Os textos listados seriam manuais de literatura brasileira porque retomam um discurso classificatório e pressupõe julgamento critico diante da tradição literária. Acreditamos que sua utilização reiterada ao longo das últimas décadas cria um diálogo interno que reforça a abordagem de determinados autores e obras como representantes da tradição literária no Brasil. Este aspecto possibilita a compreensão destes livros como agentes se não de confirmação, mas de veiculação de valores ligados ao Canon. ${ }^{3}$

Lembramos que algumas das reflexões propostas neste artigo provem de discussões realizadas dentro dos projetos de pesquisa: "O ensino de literaturas em Língua portuguesa em escolas estaduais de Campo Grande/MS", projeto aprovado pelo Edital Universal 14/2009 do FUNDECT e "O ensino de literaturas em Língua portuguesa em escolas de Campo Grande/MS", projeto aprovado pelo Edital MCTI /CNPq

\footnotetext{
${ }^{3}$ Um exemplo deste diálogo é a retomada em autores como Bosi (1993) e, em alguns aspectos, Coutinho (1969) e Candido (2000) de posicionamentos críticos observáveis em dois textos fundadores: A literatura no Brasil, de Silvio Romero (1888) e, antes dele, Bosquejo da História da poesia brasileira, publicado por de Joaquim Norberto de Sousa Silva, em 1841 e, reeditado em $2002 \mathrm{com}$ a organização e notas de Roberto Acízelo de Souza, mas sob o título de História da literatura brasileira e outros ensaios. Remetemos o leitor ao artigo "Considerações sobre Canon literário", publicado nos Anais do XIX Seminário do CELLIP em 2009 no qual abordamos mais detidamente esta relação.
} 
/MEC/CAPES $N \cong 07 / 2011$. No desenvolvimento do artigo discutiremos a influência dos MAP no ensino de literatura, bem como o distanciamento dos leitores em formação de obras literárias Strictu Senu na Educação Básica. Por fim, construiremos uma reflexão a partir do método linear de leitura literária, tendo como foco a obra de Sousândrade um dos autores trabalhados no projeto de extensão "Oficina de leitura literária"; ação desenvolvida como intervenção em decorrência dos resultados obtidos nos projetos de pesquisa mencionados há pouco.

Procuraremos enfatizar, como um dos objetivos deste estudo, a importância do enfrentamento do texto literário Stricto Sensu em ambiente escolar. Entendemos que sua focalização, para além da fragmentação teóricas e metodológicas presentes nos MAP, é uma alternativa pertinente ao ensino de literatura na Educação Básica.

\section{Materiais de apoio pedagógico: questões}

$\mathrm{Na}$ introdução do livro didático Língua, Literatura \& redação, de José de Nicola Beth Brait (apud NICOLA, 1999, p. 1) comenta, apresentando uma avaliação favorável ao texto, que uma das qualidades do livro está na "rigorosa adequação dos conteúdos e da forma de tratá-los, às exigências informativas e didáticas requeridas pelo texto suporte do ensino e do aprendizado". Pensado como exemplo de LD destinado ao Ensino Médio teríamos na obra de NICOLA (1999) a utilização do texto literário em atividades práticas como exercícios de leitura, adequação de estilo e abordagem de características estéticas frente às normas historiográficas paradigmáticas.

Fazendo a ressalva de que utilizamos os excertos que seguem como metonímia, damos um exemplo.

\section{Características do Arcadismo}

Os modelos seguidos são clássicos, Greco-latinos e renascentistas; a mitologia pagã é retomada como elemento estético. Daí a escola também ser conhecida como Neoclassicismo.

Inspirados na frase de Horácio Furgere urbem (Fugir da cidade) e levados pela teoria de Rousseau acerca do "Bom selvagem", os árcades voltam-se para a natureza em busca de uma vida simples, bucólica, pastoril. É a procura do lócus amoenus, de um refúgio ameno em oposição aos centros urbanos monárquicos; a luta do burguês culto contra a aristocracia se manifesta na busca da natureza. (...) ( NICOLA, 1999, p. 207, volume 1)

A busca da simplicidade

Fundamentalmente antigongórico, o movimento árcade tinha por emblema um meio braço segundo um padrão - foice de cabo curto - e o lema Inutilia truncat (cortar as inutilidades). Visava com isso cortar os 
exageros, o rebuscamento e a extravagância características do Barroco, retomando um estilo literário mais simples, em que prevalecesse a objetividade do mundo burguês. Os modelos seguidos eram os clássicos greco-latinos e os renascentistas; a mitologia pagã foi retomada como elemento estético. Daí a escola tornar-se conhecida também como Neoclassicismo. (TERRA; NICOLA; FLORIANA, 2002, p. 364)

\section{(...)}

\section{Características do Arcadismo}

O Arcadismo tinha por lema a frase latina Inutilia Truncat (cortar, suprimir as inutilidades). Visava com isso cortar os exageros, o rebuscamento e a extravagância característicos do Barroco, retornando a um estilo literário mais simples, em que prevalecesse a objetividade do mundo burguês. Os modelos seguidos eram os clássicos Greco-latinos e os renascentistas; a mitologia pagã foi retomada como elemento estético. Inspirados no poeta latino Horácio, os árcades cultivam o carpe dien, que consiste no princípio de viver o presente, "gozar o dia", pois o tempo corre célebre, e o furgere urbem (fugir da cidade), o abandono dos centros urbanos (...) (TERRA; NICOLA, 2008, p.383-384)

Nos três fragmentos, aquém do evidente jogo de paráfrases, encontramos definições complexas, como as dos conceitos latinos - em itálico - sem uma prévia discussão. Além disso, a tendência em descrever características estéticas complexas de maneira sintética "O Arcadismo tinha por lema a frase latina Inutilia Truncat" figura como forma de resumir o estilo, fato que naturalmente implica na equalização das nuances individuais das obras literárias e na consequente minimização de efeitos de sentido presentes nos textos literários vistos de maneira panorâmica e como exemplos das considerações críticas apresentadas sobre o movimento, no caso, o Arcadismo.

Ao apresentar de forma simplificada a diversidade de textos presentes no escopo literário, retomando Braith (apud NICOLA 1999), o LD atinge "às exigências informativas e didáticas requeridas pelo texto suporte do ensino e do aprendizado". Não questionando a validade da perspectiva apresentada por Braith (apud NICOLA 1999) os exemplos passam a impressão de que para "saber" literatura basta decorar ou apreender as características comuns a determinado período literário e compreender os excertos literários presentes nos textos como exemplos destas considerações. A opção didática do exemplo dado parece ser listar conteúdos estilísticos de maneira homogênea e apresentar uma visão paradigmática que filtra a tradição em busca de constantes de um determinado "estilo de época". Entendemos, no entanto, para além da validade paradigmática do LD que esta postura resume uma complexa rede de organização estética e temática a um conjunto homogêneo o que minimiza a diversidade estética de movimentos literários, no mínimo, mais complexos.

Vejamos o que diz sobre o Arcadismo e o Neo-Clássico Alfredo Bosi (1993) em 
um dos compêndios mencionados no início deste estudo:

\begin{abstract}
A Arcádia enquanto estilo melífluo, musicalmente fácil e ajustado a tempos bucólicos, não foi criação do século de Metastásio: retomou o exemplo quatrocentista de Sannazaro, a lira pastoril de Guarani (II Pastor Fido) e, menos remotamente, a tradição anticultirsta da Itália que se opôs à poética de Marino e as vozes que na Espanha se haviam levantado contra a idolatria de Gongora. Mas o que já se postulava no período áureo do Barroco em nome do equilíbrio e do bom gosto entra, no século XVIII, a integrar todo um estilo de pensamento voltado para o racional, o claro, o regulador, o verossímel; e o que antes fora modo privado de sentir assume foros de teoria poética, e a Arcádia se arrogará o direito de ser, ela também, "philosophique" e digna versão literária do lluminismo vitorioso" (BOSI, 1993. p. 55)
\end{abstract}

Compreendendo a opção natural pela redução explicativa como uma característica dos textos didáticos, concordando com Brait (apud NICOLA 1999) encontramos, também, nos manuais de teoria e crítica literária uma tendência em limitar as considerações aos aspectos gerais dos movimentos literários como perceptível no excerto de Bosi (1993, p.55) e exemplificado no fragmento que segue "estilo melífluo, musicalmente fácil e ajustado a tempos bucólicos". No LD, porém, a presença deste percurso facilitador que reduz o Arcadismo, conforme Bosi (1993), a "'philosophique' e digna versão literária do lluminismo vitorioso" segue-se a utilização de exercícios interpretativos direcionados aos excertos e textos literários. Esta opção, no entanto, em muito reduz as discussões sobre a diversidade e qualidade intrínseca do texto literário Stricto sensu ao fugir da abordagem do texto literário em sua complexidade imanente.

As Cartas chilenas completam a obra de Gonzaga. São poemas satíricos, escritos em linguagem bastante agressiva, que circulam em Vila Rica pouco antes da Inconfidência Mineira. Apresentam versos decassílabos e têm a estrutura de uma carta, assinada por Critilo (Gonzaga) e endereçada a Doroteu (Cláudio Manuel da Costa). Nessas cartas, Crítilo, habitante de Santiago do Chile (na verdadeVila Rica) narra os desmandos e as arbitrariedades do governador chileno, um político sem moral, despótico e narcisista, o Fanfarrão Minésio (na realidade, Luís da Cunha Meneses, governador de Minas Gerais até pouco antes da Inconfidência) (TERRA; NICOLA, 2008, p. 385)

Os excertos de Terra e Nicola (2008) compreende a apresentação de uma lista de características que, em alguns casos, abordam obras literárias de compleição mais sintética como o conto e o poema e, em sua grande maioria, utiliza apensas fragmentos de obras, seguidas de apresentação de informações biográficas - "na realidade, Luís da Cunha Meneses, governador de Minas Gerais até pouco antes da Inconfidência" - de 
forma a apresentar uma linearidade de focalização dos textos reduzindo-os a informações de contextualização e apresentação estética que evita a discussão específica do texto e minimiza a abordagem de conceitos complexos como, por exemplo, a "sátira" no excerto citado.

As simplificações da diversidade e complexidade de obras literárias passam a ser, em nosso ponto de vista, um dos problemas apresentados nos compêndios e, principalmente, nos LDs. Soma-se a esta característica a construção de listas de autores e a cobrança de leituras com objetivos específicos, ler para fazer uma prova, por exemplo, e teremos o perfil do ensino de literatura no escopo dos entrevistados na Educação Básica no recorte de nossas pesquisas.

Estas simplificações fogem a análise detida do texto literário Stricto Sensu em ambiente escolar. A comprovação desta afirmação é encontrada na análise de depoimentos de alunos entrevistados nos dois projetos de pesquisa que dão suporte a esta reflexão. Lembramos que, para este artigo, selecionamos 38 alunos matriculados em 10 escolas de Campo Grande/MS e 20 alunos de graduação em Letras. Optamos por manter o anonimato, tanto das instituições de ensino quanto dos alunos como forma de preservar a identidade dos entrevistados.

Dos 38 entrevistados da Educação Básica apenas 2 conseguiram comentar o enredo das leituras literárias realizadas ao longo do ano letivo anterior. Este dado demonstra que, em linhas gerais, os entrevistados apresentam um distanciamento do texto lido. Nas respostas que apontam para este distanciamento encontrarmos depoimentos como estes:

\footnotetext{
"Não me lembro da leitura, foi solicitada apenas para a prova" (entrevistado 13);

"Não li as obras, só resumos" (entrevistado 24);

"É difícil ler, não tenho tempo. Peguei o resumo na internet" (entrevistado 22)
}

Este perfil - ler resumos e sem muito tempo para reflexão - não é diferente nas respostas dadas por alunos de graduação em Letras. Dos vinte acadêmicos entrevistados, apenas 01(um), diz ler obras literárias na integra. Os demais afirmam ler fragmentos teóricos e resumos para adequar estas leituras às solicitações das aulas de literatura e teoria literária. Dos entrevistados, todos - Educação Básica e Graduação em letras - são unanimes em afirmar que gostam de ler textos literários, mas o tempo destinado à leitura é escasso. Treze dos entrevistados da Graduação apresentam 
respostas que podem ser agrupadas na resposta de um dos entrevistados: "leio, mas o tempo é curto e prefiro buscar referências e artigos da internet". Os demais, 07 (sete), afirmam ler apenas para adequar sua leitura a exigências do currículo, sendo que apenas um indica ler obras na integra e consegue comentar a leitura realizada.

Estas respostas possibilitam a inferência de que também na graduação encontramos uma situação fragmentada ligada a leitura literária no escopo de nossa investigação. Pelo que parece, o texto literário perde progressivamente espaço em ambiente de ensino. Esta ideia apresenta uma conclusão em prolongamento: como se lê fragmentos de textos na Educação Básica, na graduação a distância progressiva dos leitores diante do texto literário Stricto Sensu parece ser um desdobramento natural.

Esta percepção, embora metonímica, dado o recorte da pesquisa aqui apresentado, indica que a abordagem do texto literário Stricto sensu, enquanto diversidade estética específica é prejudicada na Educação Básica e na Graduação em Letras.

\section{Relato de experiência: um projeto de intervenção}

Como forma de justificar a necessidade da presença específica do texto literário em ambiente de ensino; apresentamos, em seguida, uma proposta de intervenção ao ensino de literatura que tem como premissa a discussão do texto literário Stricto Sensu. A proposta é proveniente de uma ação de extensão conjugada com os dois projetos de pesquisa que dão suporte a esta discussão. Sua apresentação é proveniente de uma inquietação: por que não apresentar e discutir textos literários Stricto Sensu em sala de aula?

O projeto de extensão "Oficina de leitura literária" é desenvolvido desde 2009 na UEMS de Campo Grande e tem como público alvo alunos da Educação Básica e, como ministrantes, acadêmicos de Letras da Universidade Estadual de Mato Grosso do Sul, unidade universitária de Campo Grande/MS. A proposta é uma adaptação do Método linear de contação de histórias, de Fanny Abramovich (1997). A ideia é ler e discutir textos literários em um contexto de interação direta entre leitores e o texto.

Passamos, antes de iniciar a discussão dos resultados da ação, a necessidade de uma breve apresentação do que denominamos "Método linear de leitura literária". Como dito, utilizamos como base para nossa proposta metodológica uma adaptação do Método linear de contação de histórias de Fanny Abramovich (1997). Nesta adaptação, 
enfatizamos na leitura do texto sua especificidade estrutural. Evita-se, portanto, a leitura dramatizada ou a utilização de aspectos cênicos na apresentação do texto ao público alvo. A ideia é obedecer à pontuação e ao ritmo do texto, utilizando-se de um tom constante na voz durante a leitura.

O primeiro passo é organizar o público alvo em círculos ou semicírculos, evitando o modo habitual de organização da sala de aula em fileiras horizontais/verticais. Tal organização permite que o professor/leitor (alunos de graduação em Letras) veja e seja visto por todos os envolvidos durante a leitura e possa, eventualmente, mediar possíveis intervenções.

Após a organização da sala o professor/leitor apresenta o texto por meio de uma pequena introdução, na qual comenta o tema do texto selecionado, os motivos da seleção e faz um pequeno histórico biográfico e bibliográfico do texto e do autor. A intenção nesta apresentação é verificar a empatia do grupo diante do texto que será lido. Feita a introdução ocorre o inicio da leitura que não é interrompida durante sua realização. Após a leitura inicia-se o debate do texto, dando voz aos ouvintes e, por fim, a confecção dos pós-textos.

É importante que após a leitura e confecção de pós-textos que o publico alvo possa comentar suas produções na interação com o texto lido. Ao pedir aos ouvintes, após a realização de uma discussão sobre as impressões obtidas, que comentem suas produções o professor/leitor pode verificar em que medida o texto atingiu o leitor. Em sua maioria, os ouvintes optam pela produção de um novo texto escrito, por manifestações orais, confecção de desenhos ou qualquer outra elaboração, incluindo, pinturas com giz de cera, canetinhas coloridas ou tinta guache. O importante, no método linear, portanto é colocar o leitor em uma interação direta com o texto lido e oportunizar a ele, ouvinte/leitor, a possibilidade de manifestar sua impressão de leitura comentando primeiro o texto lido no debate e, posteriormente, sua produção pós-textual.

Ao promovemos o contato dos leitores com textos literários acreditamos criar um espaço de enfrentamento específico da diversidade literária e, com isso, contribuir com a formação de um leitor que apresenta interesse pela leitura realizada uma vez que tem a possibilidade de emitir sua impressão sobre a leitura.

Como exemplo de uma das atividades desenvolvidas na proposta, comentaremos, em seguida, uma experiência de leitura que envolve a obra poética de Joaquim de Sousândrade, definido como exemplo das atividades desenvolvidas dentro da "Oficina de 
leitura literária". Lembramos, no entanto, que no projeto trabalhamos com diferentes autores e obras sem a preocupação específica de apresentar ou filiar este ou aquele autor à determinada corrente e/ou tendência literária. A ideia é focalizar o texto literário e explorar suas particularidades para, posteriormente, caso necessário, fazer referências ao "estilo de época" ao qual o texto pertence ou dialoga.

A intenção é ampliar o contato do leitor com o texto literário e, na medida do possível, com as demais manifestações artísticas. Ressaltamos, naturalmente, que as considerações resultam do debate em relação ao texto selecionado e, por isso, assumem uma versão mais formal do que a apresentação oral dentro da oficina.

\section{Sousândrade: apresentação de uma poética}

Ao apresentarmos a obra de Sousândrade no contexto da proposta da oficina discutimos a expectativa do público alvo em relação a poemas como: "Se se morre de amor" e "Canção do exílio", de Gonçalves Dias. Exploramos, nesta introdução, as considerações orais sobre certa emotividade presente nos poetas românticos brasileiros. A ideia da presença da subjetividade, da melancolia e de uma tendência aos temas passionais comumente veiculadas nos LD foram relacionadas, pelos ouvintes, ao Romantismo, algo esperado na medida em que o publico alvo frequenta o Ensino Médio e grande parte , 20 dos envolvidos, frequentam o $3^{\circ}$ ano. Feita a discussão, de maneira oral, dos dois poemas de Gonçalves Dias iniciamos a apresentação da poética de Sousândrade, dando enfoque ao aspecto inovador não só de sua poesia como por meio da apresentação de seu inusitado perfil biográfico.

Após esta apresentação iniciamos a leitura de alguns fragmentos do poema 0 guesa, com o objetivo de apresentar a obra do poeta maranhense aos ouvintes. Como dito, preferimos, neste artigo, sistematizar as informações transmitidas de forma oral durante a atividade na "Oficina de leitura literária". Lembramos que as atividades foram realizadas em três encontros de duas horas semanais em um total de 06 seis horas de atividades.

Organizamos as ações desenvolvidas na oficina em um texto que sintetiza as considerações apresentadas, bem como a análise dos textos de Sousândrade desenvolvidas na ação. 


\section{Apresentação de Sousândrade: preliminares ${ }^{4}$}

Joaquim de Sousa Andrade nasceu na Vila de Guimarães, comarca de Alcântara, na Fazenda Nossa Senhora da Vitória, às margens do rio Pericumã, estado do Maranhão, em 9 de julho de 1832. Teve uma infância difícil em decorrência da prematura morte dos pais, fato que marcaria profundamente a vida do autor. Do período de 1853 a aproximadamente 1856, após ver negado um pedido de ajuda financeira para custear os estudos na Europa, feito ao imperador D. Pedro II, vende parte de suas posses e parte para a Europa. Nesse período, provavelmente cursa Letras pela Sorbonne e Engenharia de Minas, cursos que provavelmente não concluiu. Em passagem pela Inglaterra, é convidado a se retirar do país por ter atacado, num artigo de imprensa, a rainha Vitória.

De volta ao Brasil, no ano de 1857, faz sua estréia literária com a obra Harpas selvagens. Em 1858, o poeta viaja pela Amazônia, onde coleta informações sobre o culto do Jurupari, anotações essas que, posteriormente, utiliza na composição do Guesa. No ano de 1864, casa-se com Dona Mariana de Almeida e Silva, viúva de abastado fazendeiro, com a qual tem uma filha: Maria Bárbara. No período de 1867 a 1868 são publicados, no Semanário Maranhense, dirigido por Joaquim Serra, fragmentos dos dois primeiros cantos do Guesa. Em 1868, o poeta publica Impressos - 1ำ vol, contendo poesias diversas e os Cantos I e II do Guesa. No ano seguinte, sai Impressos - $2^{\circ}$ vol, contendo o Canto III do Guesa.

Provavelmente, no ano de 1870, separa-se da esposa legítima, pois já em 1871 , acompanhado da filha, fixa residência nos EUA. Educa a filha Maria Bárbara no Colégio Sacred Heart em Manhattanville, Nova lorque. Nesse período, o poeta entra em contato com a agitação do capitalismo norte-americano e a bolsa de valores de Wall Strett, fator extremamente importante para a composição do Canto $X$ do Guesa. Nesse mesmo período, trabalha como secretário e colaborador do periódico $O$ Novo Mundo, publicado em português em Nova lorque.

Em 1874 faz imprimir, também em Nova lorque, o $1^{\circ}$ volume de suas Obras poéticas (nessa obra aparecem os Cantos de I a IV do Guesa Errante, além das obras Eólias e Harpas Selvagens). Em 1876, publica os Cantos V a VII (incompleto) do Guesa. No ano seguinte, vem a lume a última edição nova-iorquina que tem o Canto VIII (Canto $X$ da versão londrina). Provavelmente, no ano de 1888, publica em Londres a versão mais atualizada do Guesa. Nessa edição, o Canto VIII da edição nova-iorquina aparece como

${ }^{4}$ Os comentários críticos e biográficos sobre o autor foram recuperados de CAMPOS (1979) e Williams (1979). 
Canto X. Em 1889, já de volta ao Brasil, envia, de São Luís do Maranhão, um telegrama de saudações ao Marechal Deodoro da Fonseca, felicitando-o pela Proclamação da República. No mesmo ano, é nomeado membro da Junta Provisória Municipal de São Luís.

Ingressando na vida política, é candidato, em 1890, a senador, mas acaba renunciando. No mesmo ano, idealiza o desenho da Bandeira do Estado do Maranhão. Em 1893, publica Novo Éden, poemeto da adolescência, provavelmente escrito entre 1888 e 1889. No ano seguinte, é contratado para lecionar Grego no Liceu Maranhense, seu primeiro emprego. Sonha com a criação de uma universidade popular, a qual nomeia Universidade Nova Atenas, mas já sem condições financeiras para concretizar o sonho imagina os regulamentos da instituição, a forma de sua bandeira, chegando mesmo a promover reuniões em sua Quinta para discutir a implantação da Universidade.

No ano de 1899, aparece pela última vez em público, proferindo o discurso de saudação a Coelho Neto, quando em visita ao Maranhão. Provavelmente, nesse mesmo ano, a esposa e a filha se transferem para Santos. Sem condições financeiras o poeta, para se manter, vende as pedras dos muros da sua arruinada "Quinta Vitória". Tido como louco, passa a perambular pelas ruas de São Luís sendo, inclusive, alvo de brincadeiras de moleques que the atiram pedras, fato que obriga o Governador Lopes Leão a tomar medidas de segurança para proteger o poeta. Em 1902, vem a lume, em O Federalista, "O Guesa, o Zac" (continuação do Canto XII do Guesa). No dia 21 de abril, do mesmo ano, os alunos do Liceu Maranhense encontram-no gravemente enfermo em sua Quinta Vitória. Transportado para o Hospital Português, falece no mesmo dia.

Diz a "lenda" que os últimos originais do poeta foram utilizados como papel de embrulho ou mesmo queimados. O certo é que sua obra permaneceria no abandono até meados do século $\mathrm{XX}$, quando seria novamente colocada em circulação pelos irmãos Campos (1979).

O poema $O$ Guesa é organizado em XIII Cantos, dos quais ficaram inacabados os Cantos VII, XII, e XIII. ${ }^{5}$ Estudos feitos por autores como Frederick G. Williams (1976), Luiza Lobo (1986), Haroldo e Augusto de Campos (1979), entre outros, apontam para a importância do périplo da personagem central do poema como ponto importante para a

\footnotetext{
${ }^{5}$ Muitos críticos têm afirmado que o Canto VI do poema está incompleto. Embora realmente este Canto apresente uma certa irregularidade, não o consideraremos inacabado, uma vez que o poeta o deu como concluído ao não mencioná-lo na edição definitiva do poema, na qual encontramos: "Ficam interrompidos os Cantos: VII, XII, XIII do poema O Guesa" (O Guesa. Canto XIII, p. 350)
} 
compreensão, pelo menos superficial, da estrutura organizacional do texto. Concordando com esses críticos, faremos uma breve exposição do deslocamento espacial da personagem Guesa ao longo do texto. Para tanto, como já foi dito, levaremos em conta o périplo da personagem, buscando, sempre que possível, discutir as implicações subjetivas atribuídas pelo eu-poético em relação ao cenário descrito.

Lembramos, no entanto, que ao final da apresentação do poeta o público alvo manifestou interesse pela biografia de Sousândrade. Aproveitando este interesse chamamos a atenção para a relação entre a poética de Sousândrade e sua inusitada biografia. Esta relação criou nos ouvintes uma expectativa positiva para a leitura dos fragmentos do poema, algo que julgamos relevante mencionar neste estudo.

Como forma de organizar a leitura dos fragmentos, chamamos a atenção para um aspecto do poema, a questão do périplo do personagem.

\title{
Poética de extremos: ironia
}

Os Cantos I, II e III de O Guesa podem ser considerados como momentos de busca pelas origens míticas do poema. Essa noção pode ser percebida se pensarmos no início idílico encontrado no Canto I. Nele o Guesa se refere, por um lado, à exuberância da natureza americana e, por outro, à crueldade do colonizador, visto pejorativamente como elemento degradante para a paz primitiva:

\author{
Candidos Incas! Quando já campeiam \\ Os heroes vencedores do innocente \\ Índio nú; quando os templos s'incendeiam, \\ Já sem virgens, sem oiro reluzente, \\ "Sem as sombras dos rêis filhos de Manko, \\ Viu-se... ( que tinham feito? e pouco havia \\ A fazer-se... ) n'um leito puro e branco \\ A corrupção, que os braços estendia! (O Guesa, Canto I, p. 3) ${ }^{6}$
}

Neste fragmento, percebemos o percurso descrito acima, pois a adjetivação "candidos" e "innocente", atribuída aos Incas, remete à pureza do primitivo antes do contato com o estrangeiro. O perder as "virgens" e o "oiro" denuncia a visão negativa associada ao estrangeiro, que contamina com sua cobiça a pureza virginal dos nativos. $O$ espanto interrogativo exposto no verso entre parênteses é uma solução genial do poeta para expressar a indignação do eu-poético frente à atrocidade imposta pela cultura

\footnotetext{
${ }^{6}$ Será resguardada a ortografia original do poema, mesmo que em alguns momentos esta apresente algumas incorreções aos olhos da norma culta vigente. O texto fonte será sempre: SOUSÂNDRADE, J. $O$ Guesa .Edição fac-similar. Org. Jomar de Morais. São Luís/ MA : SIOGE, 1979.
} 
colonizadora ao nativo.

Essa indignação será percebida com mais clareza no Canto II, no qual o indígena assume a identidade do europeu em detrimento de suas particularidades culturais, perdendo, com isso, sua pureza inicial. A exposição dessa participação do nativo no processo de colonização faz com que o traço interno também seja criticado, pois passa a ser visto como elemento propagador da ação colonizadora. A dança pandemônio "Tatuturema", contida no interior deste Canto II, funcionaria como um índice da situação imposta ao nativo com a equiparação a um parâmetro externo.

Nesta medida, a referência à nudez do índio, diante da queimada dos templos, no fragmento citado do Canto I, pode ser vista como um índice da participação ativa do nativo na degradação de sua cultura, pois este assiste passivamente à ação do estrangeiro e, com isso, nega sua matriz primitiva para, posteriormente, assumir o paralelo externo como determinante de seus valores culturais.

Na socegada lavra, esperançosas

Tangendo o boi do arado. O povo infante

O coração ao estupro abre ignorante

Qual ás leis dos Christãos as mais formosas.

Mas, o egoismo , a indiferença, estendem,

As éras do gentio; e dos passados

Perdendo a origem chara estes coitados,

Restos de um mundo, os dias tristes rendem.

Quanta degradação! Razão tiveram ...

(O Guesa, Canto II, p. 21)

A alusão ao povo infante, que perde sua identidade cultural, é aproximada à imagem do nativo vítima da ação externa. O verbo "estendem", no entanto, coloca o nativo como participante da ação corruptora, pois "as éras " do gentio deixam de remeter à pureza virginal para ser entendida como a propagação do "egoismo".

O Canto II deflagra, assim, a degradação cultural do elemento interno, pois o nativo aparece como parte integrante deste processo.

\author{
( Um delegado em scismas) \\ - Reina a paz em Varsovia: \\ Mas, a guerra a chegar, \\ Recrutamos arraus, \\ Picapaus, \\ Quando a luz se apagar.
}

(O Guesa, Canto II, p.35)

A participação do nativo no processo de degradação cultural pode ser percebida, 
na medida em que elementos naturais como "arraus" e "picapaus" aparecem recrutados para a "guerra". A luz que se apaga indicaria justamente a descaracterização do traço genuíno da brasilidade, pois o olhar para fora transforma o interno, apontando para a perpetuação da degradação. A referência à "paz em Varsovia" soa como ironia, uma vez que o elemento interno é ligado a um universo exterior em paz, o que pode indicar um conflito interno, no qual os traços de brasilidade tensionam com a exterioridade.

O Canto III tem como cenário a exuberância do espaço amazônico; no entanto, o Guesa aparece dormindo: "Dormindo o Guesa está. Negrantes coroas"[p.46]. O ambiente descrito é aproximado a um sonho, no qual figuram quatro personagens: uma figura maternal, uma imagem mítica (Uyara, deusa protetora das águas na mitologia tupi); uma metafísica (Chaska, lua para os incas) e a musa Virjanüra ${ }^{7}$.

Estas personagens, envoltas no sonho, funcionariam como iconização da própria natureza brasileira, uma vez que o poema as coloca em um paralelo direto com o ambiente brasileiro.

Deusa dos roçagantes véus doirados!

Se me aparto de ti, quantos cuidados,

Quantas saudades tenho de deixar-te!

Ó noites do Amazonas! Ó formosas

Noites d'enlevos! Tão enamoradas!

Alvas, tão alvas! E as canções saudosas,

Incantos do luar, sempre cantadas!

Foi este o prazo ... Virjanura a esta hora

Também te olhando está ... muda e pendida

A visão branca da montanha erguida,

Que longa noite espera, espera - a aurora. ( O Guesa, Canto III, p. 56)

A inquietação do eu-poético perante a "Deusa dos roçagantes véus doirados" remete a uma idealização da figura feminina que transcende a mera projeção física para concretizar um paralelo mais amplo: a natureza brasileira. A tristeza do eu-poético face à despedida do ambiente nacional transporta a musa a um ícone da natureza brasileira. $\mathrm{O}$ olhar dos Andes, "a visão branca da montanha erguida" sobre a exuberância do espaço nacional implica, nesta medida, a deflagração do nacionalismo sousandradino metaforizada na "aurora".

O Canto IV é marcado por uma profunda afetação romântica, pois o eu-poético

\footnotetext{
${ }^{7}$ Neologismo sousandradino formado pela fusão das palavras : virgem e pura. Tal procedimento remete a uma caracterização romântica da figura feminina.
} 
surge como projeção amargurada diante da contaminação do elemento natural. O Guesa aparece, neste fragmento, como um espectro montado em um cavalo, presenciando a degeneração de sua pátria, metaforizada em um incêndio que assola o espaço natural. A alusão explícita à morte de Gonçalves Dias, contida neste Canto, indica uma visão pessimista em relação ao espaço interno.

Do fundo espesso a nuvem tremulante.

"O Sol raiando beija a onda brilhante

Onde Gonçalves - Dias sepultou-se! ( O Guesa, Canto IV, p. 70)

Tais versos remetem a uma metalinguagem imanente ao poema, podendo ser vista como índice da situação degradada do espaço nacional em contraposição ao ideal utópico apresentado em "Canção do exílio", de Gonçalves Dias.

Dos gózos era o escravo: onde as mulheres

Luzissem meigo olhar; onde os perfumes

Fossem berço de zephyro e prazeres

Da florea varzea e os levantados cumes,

Alli vivia o Guesa - entre os desmaios

Das brancas fórmas, das visões ethereas

Que ao luar s'incantam, entre os raios

Que a amar derrama - celestiaes materias!

(O Guesa, Canto IV, p. 69)

As referências a figuras femininas degeneradas e a indicação da luxúria e da devassidão, "onde as mulheres luzissem meigo olhar "(prostíbulo), remetem a alienação própria do espírito romanesco, pois os últimos versos se referem a uma visão carnal do amor.

No Canto V, temos uma espécie de intensificação do teor nacionalista, pois o fluxo de consciência proporciona um regresso ao Maranhão e, ao mesmo tempo, leva o eupoético à evasão romântica, à infância e à figura materna. Neste Canto, o poema denuncia a degeneração moral da sociedade brasileira.

E onde estão os villões civilizados

Foram os selvagens, livres na investida

Á sombra de suas settas resguardados,

No amor da gloria e da luctada vida;

Uns, viciosos; outros, forasteiros;

Todos ao mesmo abysmo - que os não chama, 
Nem d'onde os não evocam. Extrangeiros, Tupan ou Theos, quem a luz derrama? (O Guesa, Canto V, p. 92-93)

Neste excerto, podemos perceber a visão do estrangeiro como elemento negativo, pois os "villões" são civilizados e, portanto, "extrangeiros" (sic). Os vícios trazidos pelos estrangeiros imprimem, assim, a degeneração moral da cultura brasileira. $O$ nativo, lançado ao "mesmo abysmo" que o forasteiro, indica a fusão entre os planos civilizado e selvagem. A descaracterização do nativo figura, desta forma, como um processo de esvaziamento da pureza nativista percebida na aproximação entre o Deus nativo "Tupan" e a imagem do Deus cristão "Theos", que, ironicamente, são postos lado a lado.

$\mathrm{A}$ viagem à Corte, cantada no Canto VI do poema, remete a um aprofundamento da descaracterização do nativo.

\author{
Oh, quanta luz ! Nos valles jaz mesquinha \\ A cidade, negra harpa, que recorda \\ Creações de Caïn : jardins e vinhas; \\ Ruas sonoras são-lhe da harpa as chordas. (O Guesa, Canto VI, p. 131)
}

A referência a um "abysmo" indica a destituição do olhar positivo atribuído ao nativo, que tem seus preceitos éticos e morais ligados à idéia de traição, metaforizada na figura bíblica de "Caïn". A melancolia face ao traço interno remete diretamente ao Canto II, mas, além disso, indica uma visão depreciada do mundo. A intertextualidade bíblica encontrada na figura de "Caïn", símbolo da traição por ter traído e matado seu irmão Abel na liturgia cristã, remete à distância entre o plano idealizado e a realidade nacional. $A$ feroz crítica a uma "falsa independência" ganha contornos definitivos na indicação satírica à família real portuguesa8: "Aqui Pedro - Bragança co'a victoria / D'independência, pela liberdade." [p. 136]. Nestes dois versos, temos uma visão sintética do olhar apresentado no Canto VI.

A vitória da "independência" sugere a derrota da "liberdade", o que lança o brasileiro a uma situação de escravidão em relação ao externo. Tal postura é perceptível ao longo de todo o poema, mas se torna mais nítida neste Canto, uma vez que sintetiza a crítica imposta pelo eu-lírico em relação a sua sociedade. No Canto X, temos, no chamado "Inferno de Wall Street, uma nova intensificação desta crítica social.

\footnotetext{
${ }^{8}$ Muitos críticos, entre eles os irmãos Campos (1964) relacionam este Canto à resignação do poeta em relação à monarquia brasileira, mas, como aponta Lobo (1986), tal postura implica uma redução simplória do poetar sousandradino. Preferimos encarar as constantes referências à família imperial brasileira como uma forma de deflagração da espoliação do estrangeiro em relação ao nativo.
} 
Pode-se dizer que o Canto VII representa um momento de fuga, tendo como cenário o espaço europeu, mas infelizmente, por ter ficado inacabado, não oferece maiores possibilidades de análise. Cabe ressaltar, entretanto, que este Canto poderia contrastar com o Canto VI, uma vez que temos nele a alusão à figura bíblica de Abel:

Já consternado, o coração do Guesa

Vibrou; e erguendo-se a moral belleza,

Resgatou-a; de asylo religioso

Sagrou-Ihe a educação co'a divindade

De quem traidor disciplo ama zeloso,

E diz : "se meiga flor e a liberdade"

Luz de Abel - Deus eterno! - é a vaidade.

É d'extranhos punhal : faces - amenas,

Risos evanos meigos da saudade

E flor de morte americas morenas! ... (O Guesa, Canto VII, p. 148)

O resgate do "asylo-religioso" é negado pela vaidade humana, mostrando a degeneração do ideal de pureza. Os "risos evanos", remetendo ironicamente à participação de Eva na cena do pecado inicial, indicaria que o paraíso perdido leva a "flor de morte". Nesse caso, a alusão a um "traidor zeloso" traria uma visão sintética da dominação da "vaidade" humana sobre o ideal de um homem puro voltado a Deus e à ordem moral. A alusão à "Luz de Abel" confirmaria essa leitura, pois a ação do traidor "Cain" ao matá-lo concretiza o sofrimento humano, proporcionando a consternação do Guesa com essa situação.

No Canto VIII, teríamos, novamente, um movimento de regresso às origens, ou seja, ao Maranhão. A visão sousandradina mostraria um Maranhão impregnado de nostalgia, no qual o presente remete, por um lado, à crítica à monarquia e à corrupção trazida pela cobiça ao seio republicano, por outro, a um saudosismo em relação à infância de paz ao lado da família e da figura materna. O contraste entre as figuras idílicas, associadas à família, e os elementos destruidores da pureza primitiva são metaforizados na cobiça e na podridão moral do homem.

E aos pés luziu-Ihe da fortuna o oiro

Em grandes montes, que os dos mundos frivolos Homens, e qual se fosse o oiro o thesoiro, $\mathrm{N}$ 'elle honravam qual honram falsos idolos.

(O Guesa, Canto VIII, p. 159) 
A adoração ao "oiro" remete à passagem bíblica, na qual Moisés, ao regressar da montanha, depara-se com a traição de seu povo. À luz dessa leitura, parece-nos que o poeta, graças ao seu olhar crítico, procura estabelecer um contraponto entre um elemento de pureza e a deturpação deste traço pela ação do homem. Levados pela cobiça, os homens forjam seus ideais a partir de paradigmas norteados pelo egoísmo e pela falsidade e, com isso, contaminam qualquer traço de pureza. A frivolidade do mundo, absorto na usura, cega o homem que, assim, esquece seu traço positivo para se afirmar como degradador do seus próprios ideais.

O Canto IX focaliza o deslocamento do Guesa pelo continente americano. cenário descrito será o das Antilhas, da América Central, do Golfo do México e das costas dos EUA. Neste Canto, fica latente a importância dada à natureza, tida como elemento de refúgio purificador para o homem corrompido pelo meio social.

Tu ainda á luz dos trópicos saudosa Leras 'Paulo-e-Virginia', o amor e o riso De doce creação, sempre mimosa Quando a terra no estado de paraiso :

(O Guesa, Canto IX, p. 170)

A referência intertextual à obra Paulo e Virgínia de Bernardin de Saint-Pierre (1986) pode ser entendida como uma tentativa de denunciar uma ingenuidade inata presente no seio humano. A terra em estado de paraíso estabelece uma ironia em relação à morte da heroína "Virginia", afogada no mar por receio de revelar suas formas virginais. A saudade da "luz dos trópicos" indica a natureza como ponto de refúgio para o homem atormentado pela sociedade corrompida.

O Canto $\mathrm{X}$, tendo como cenário os EUA, aponta para uma possibilidade de plenitude metaforizada na República. No entanto, a visão do espaço, corrompido pela cobiça e pela degradação moral, descaracteriza a visão eufórica, instaurando uma crítica à utopia republicana. O inferno financeiro de Wall Street mostra a impossibilidade de preservação moral do homem. O mundo da usura e da ganância figura como paradigma insuperável, sendo o homem condenado a participar ativamente do jogo.

O Canto XI pressupõe o regresso ao Brasil : o "Éden". Nesse regresso, o olhar desloca-se para o Oceano Pacífico, passando pelo Panamá, Colômbia, Venezuela e Peru. Temos, novamente, a focalização da exuberância da natureza como paliativo para o 
sofrimento gerado pelo contato com o inferno financeiro e pela decepção com a República.

Nessa mesma linha temática, o Canto XII continua a volta às origens; o espaço descrito é o da Argentina, da Cordilheira Andina, da Bolívia e do Chile. Percebemos, neste Canto, uma visão idílica do mundo, contraposta à visão aterradora do deserto.

Formosos mares! terras generosas, Onde floriu magnífico o Indiano

Ao bello Sol ( bastante a edeneas rosas)

Andeos pendores ferteis, ou medáno

Deserto quasi-ignoto! se descobre ...

(O Guesa. Canto XII, p. 311)

A aridez do deserto estabelece o contraste entre o positivo e o negativo do espaço americano. Em outra passagem, a narração exacerbada focaliza uma tormenta no mar.

Oh, a aridez terrível dos rochedos

Elevados dos ares a pureza

E a transparência ideal dos climas ledos

Alma d' Hercules! A esta natureza

Abrem-se tempestuosas penedias,

Vanzeiam, mugem, qual revoltos mares,

Onde escutam-se grandes agonias

E d'onde azas desdobram-se estellares.

(O Guesa, Canto XII, p. 319)

Podemos notar, neste canto, a visão do elemento natural como denunciador da inquietação do eu-poético. As contraposições entre amenidade e rusticidade, observadas neste fragmento, podem ser entendidas como a denúncia da lucidez do eu-poético face a uma idealização do espaço, própria do discurso romântico.

Os "ares de pureza" e o clima ledo comparados à figura mitológica de Hércules podem ser entendidos como confirmação de uma crítica ao discurso romântico. Sendo assim, o choque entre a aspereza do deserto e das rochas, associado à violência da tempestade, figura como ponto destoante em relação à percepção da natureza como refúgio do homem, ou seja, o próprio elemento natural é transfigurado em agressor do eupoético.

Caracterizando-se por uma profunda melancolia em relação à pátria, que aparece metaforizada na figura feminina de "Inti", o canto XIII ou Canto Epílogo, embora 
inacabado, poderia ser entendido como uma síntese temática do texto. Tida como "noiva", "Inti" concretiza a situação degradada vivida pelo eu-poético, que aparece enfermo. A doença que assola o Guesa, nesse fragmento, pode ser entendida como a perda da esperança. O esvaziamento do ideal de plenitude gera não só a frustração em relação ao presente, como também a eleição do futuro como ponto a ser redefinido para que esse ideal possa florescer.

Amava a patria [ Inti ], e d'ella ao pão amargo

S'elevava terrivel contra Deus;

Mais a ess'ora, formosa, a vida ao largo,'

De um cynico ministro, d'essa lama

Dicta diplomacia. Ao peito a chamma,

Ai dos divinos, dos formosos réus!

(O Guesa, Canto epílogo, p. 336)

'Resta-te a esp'rança em mim' ? gemeu minha alma

$(\ldots)$

Não te abandono; impunemente e louca

Não vem-se despertar, olhos luzindo,

A um quasi-mudo peito, porque evoca

Ao futuro - E porque loucura vindo? (O Guesa, Canto epílogo, p. 338)

A alusão pejorativa a elementos como "diplomacia", aliada a um cinismo envolto em lama, poderiam ser citados como exemplos dessa postura pessimista em relação ao presente. $\mathrm{O}$ amor à pátria resgata a esperança, metaforizada na própria imagem do futuro. O gemido da alma, ao evocar esse futuro, indica uma desesperança no novo, resultando na chegada da loucura.

A continuação do Canto XII, denominado "O Guesa, o Zac", escrito no ano de 1902, às vésperas da morte do poeta, tem como cenário o Maranhão. Neste fragmento, percebe-se um fino pessimismo em relação à pátria. A busca pela igualdade democrática aparece como elemento a ser conquistado para a efetiva concretização de uma liberdade plena em relação à prisão colonizadora.

$\mathrm{Na}$ constatação da força do povo, o olhar moderno mostra-se como única possibilidade de conquista da liberdade, tão cara a Sousândrade.

— Volta à pátria! a tua c'roa, o teu cetro

Vem na praça queimar! teu espectro

Catástrofe, à Europa, ah! ah! vai fazer rir !

Não dizias-te um Republicano?

Vem! vem ser cidadão soberano 
Como a grande maioria de seus contemporâneos, Sousândrade foi marcado por um forte nacionalismo. No entanto, a visão sousandradina, perpassada por um veio altamente crítico, denunciou a fragilidade da utopia nacionalista cantada pela maioria dos autores românticos. A ridicularização da "máscara européia" faz-se presente, neste fragmento, através do tom de galhofa produzido pelo uso das interjeições "ah! ah!". O cidadão republicano puro queima o "cetro" e se liberta do "espectro catástrofe" para, só assim, ser considerado como republicano, ou seja, um republicano brasileiro, desprovido do constante olhar externo e envolto em sua matriz cultural.

\section{Inquietações no público alvo}

Discutir o texto literário Stricto Sensu em sala de aula, no caso, o texto de Sousândrade, eleito como exemplo, é uma das maneiras de compreender nossa diversidade literária. A apresentação do autor, neste sentido, ampliou o conhecimento específico do publico sobre o Romantismo brasileiro ao apresentar outra face desse movimento.

Ao concluirmos as leituras dos fragmentos de $\mathbf{O}$ guesa, comentados neste estudo, muitos alunos demonstraram interesse pela produção do poeta. A aproximação dos fragmentos textuais aos poemas de Gonçalves Dias foi fundamental, pois provocou nos leitores/ouvintes um sentido de incompreensão em relação à homogeneidade do Romantismo no Brasil. Um desdobramento desta inquietação foi a grande quantidade de produções pós-textuais realizadas pelos alunos. A ideia de que teríamos um poeta "diferente" de Gonçalves Dias nos parece ser uma observação importante a ser feita na interação do publico alvo com o texto de Sousândrade. Lembramos que não foi objetivo da ação propor uma comparação entre autores românticos - Gonçalves Dias e Sousândrade -, antes contribuir para o acesso de leitores a obras literárias em um espaço de interação com o texto.

Mais do que apresentar um poeta, no caso Sousândrade, procuramos, neste trabalho, aludir à importância de valorizar o texto literário Stricto Senu em atividades de leitura em ambiente escolar. Pensamos, com isso, contribuir para a formação de leitores e, por contingência, ampliar a valorização da literatura ao apontar para a importância da focalização detida do texto e seu ensino, objeto primeiro deste trabalho. 


\section{CONSIDERAÇÕES FINAIS}

A questão que encerra este trabalho é a presença de uma inquietação diante da influência do cânone e da Historiografia literária no ensino de literatura. Discutir a necessidade de revisão constante do cânone literário por meio do enfrentamento detido e específico do texto literário nos parece ser um caminho profícuo a ser trilhado. Ao abordar o texto Stricto Sensu em ambiente escolar, em nosso entendimento, possibilita um caminho para a reflexão sobre a necessidade de valorização da literatura enquanto fator de construção de novos discursos e, ao mesmo tempo, um espaço para indicar lacunas no ensino de literatura no século XXI.

Entendemos que a mediação estética na construção do literário, bem como a leitura detida de textos amplia em muito o interesse pela leitura literária no contexto contemporâneo. Reconhecemos a importância da abordagem de textos teóricos e da crítica literária no Brasil; mas entendemos que sua apresentação não deve ultrapassar a relevância do texto no contexto de ensino. É por este prisma que acreditamos na necessidade da apresentar textos Stricto Sensu em ambiente escolar. Em nosso entendimento, criar espaços de debate relacionados a especificidade do literário é uma forma de ampliar o contato de leitores com a diversidade de textos na tradição.

Para concluir este trabalho, parafraseando Carlos Drummond de Andrade, afirmamos que é pela leitura e discussão do texto literário Stricto Sensu que podemos mensurar sua importância enquanto expressão cultual.

\section{REFERÊNCIAS}

ABRAMOVICH, F. Literatura infantil: gostosuras e bobices. São Paulo: Scipione, 1997.

BOSI, A. História concisa da literatura brasileira. 37.ed. São Paulo: Cultrix, 1994.

BRAITE, B. Introdução. In: NICOLA, J. de. Língua, literatura \& redação. Edição renovada e ampliada. São Paulo: Scipione, 1999. Volume 1, p. 1.

CALDEIRA, J. O cânone nos estudos Anglo-americanos.Coimbra: 1994.

CANDIDO, A. Formação da literatura brasileira. 3.ed. São Paulo: Cultrix, 2000. v. II. CANDIDO, A. Literatura e sociedade. São Paulo: Cortez, 1976. 
CANDIDO, Antonio. Formação da Literatura brasileira. 3 ed. Belo Horizonte: Itatiaia, 2002. Volume único.

CARPEAUX, O. M. História da literatura ocidental. Rio de Janeiro: Cruzeiro, 1961.

CASCUDO, L. C. da. Literatura oral no Brasil. 2 ed. São Paulo: Global, 2006.

COUTINHO, A. A literatura no Brasil. 2.ed. Rio de Janeiro: Record, 1969.

LOBO, L. Tradição e modernidade em Sousândrade. São Paulo: Contexto, 1986.

NICOLA, J. de. Língua, literatura \& redação. Edição renovada e ampliada. São Paulo:

Scipione, 1999. Três volumes.

SILVA, Joaquim Norberto Souza de. História da literatura brasileira e outros ensaios. Organização, apresentação e notas por Roberto Acízelo de Souza. Publicado originalmente em 1841. Rio de Janeiro: Zé Mário Editor, 2002.

SOUSÂNDRADE. O Guesa. (Fac-simile). Organização e notas Jomar de Morais. Marnhão: SIOGE, 1979.

TERRA, E. NICOLA, J. de. Português de olho no mundo do trabalho. São Paulo: Scipione, 2008.

TERRA, E; NICOLA, J. de; CAVALLETE, T. F. Português para o ensino médio: e produção de textos. São Paulo: Scipione, 2002. Volume único. 